\title{
Process Modeling of Deagglomeration of Ceramic Nanoparticles in Liquid Metal during Synthesis of Nanocomposites
}

\author{
Payodhar Padhi, ${ }^{1}$ Biranchi Narayan Dash, ${ }^{1}$ and Sachi Kanta Kar ${ }^{2}$ \\ ${ }^{1}$ Department of Mechanical Engineering, Konark Institute of Science \& Technology, Bhubaneswar, India \\ ${ }^{2}$ Central Tool Room \& Training Centre, Bhubaneswar, India
}

Correspondence should be addressed to Payodhar Padhi, payodharpadhi@gmail.com

Received 15 March 2011; Accepted 21 April 2011

Academic Editor: Guifu Zou

Copyright (C) 2011 Payodhar Padhi et al. This is an open access article distributed under the Creative Commons Attribution License, which permits unrestricted use, distribution, and reproduction in any medium, provided the original work is properly cited.

\begin{abstract}
The cavitation phenomenon is well known to lead to deagglomeration and uniform dispersion of nanoparticles in liquid metal. The nature of flow leading to deagglomeration, the rate of deagglomeration, and the effect of frequency of them has been systematically investigated. It is extremely difficult to experimentally know about them and thus modeling the phenomenon is indispensable. The same has been attempted in the present study. The present study attempts to model the process of deagglomeration and dispersion of ceramic nanoparticles in the vicinity of cavitation using FLUENT 6.2.16. For this a simple representative volume element has been modeled.
\end{abstract}

\section{Introduction}

The phenomenon of bubble cavitation has been found to be useful for de-agglomeration and uniform dispersion of nano-particles in liquid metal. There are many researchers who have described the bubble dynamics in details [111] but dispersion of nanoparticles due to collapse of bubbles in liquid metal is still a hot topic for research. The nature of flow leading to deagglomeration, the rate of deagglomeration, and the effect of frequency of them need to be systematically investigated. It is extremely difficult to experimentally know about them and thus modeling the phenomenon is indispensable. The same has been attempted in the present study. The present study attempts to model the process of deagglomeration and dispersion of ceramic nanoparticles in the vicinity of cavitation using FLUENT 6.2.16. [12]. For this a simple representative volume element has been considered.

\section{Mathematical Model}

A two-dimensional representative volume element (RVE), which is shown in Figure 1, was selected to understand the flow behavior and kinetics of deagglomeration at mesoscopic scale. The two-dimensional representative volume element consists of a single agglomerate consisting of nanoparticles. The agglomerate was assumed to be circular. The flow at the boundaries $\mathrm{AB}, \mathrm{BC}$, and $\mathrm{CD}$ was assumed negligible for computational simplicity. On one side (DA) of the representative volume element, a surface of bubble (assumed static) with $100 \mu \mathrm{m}$ diameter generates pressure shock wave as a result of collapse. Therefore, pressure boundary condition was applied in the semicircular portion of the side DA (shown in Figure 1) and no slip condition was applied in the remaining portion of DA. The semicircular boundary, taken as the bubble wall, was subjected to a sinusoidal pressure variation using user-defined function (UDF) in FLUENT 6.2.16. Thus it has been assumed that bubble collapse is taking place at the same location of the RVE after regular intervals of time.

Although during the collapse the dimension of the bubble changes, for simplicity it has been kept static. Since the size of bubble is small compared to the representative volume element and through the mathematical model only a rough estimate of the dispersion time is aimed at, the assumption is justified. Also convective movement of the bubble has been ignored. The assumption of negligible flow 


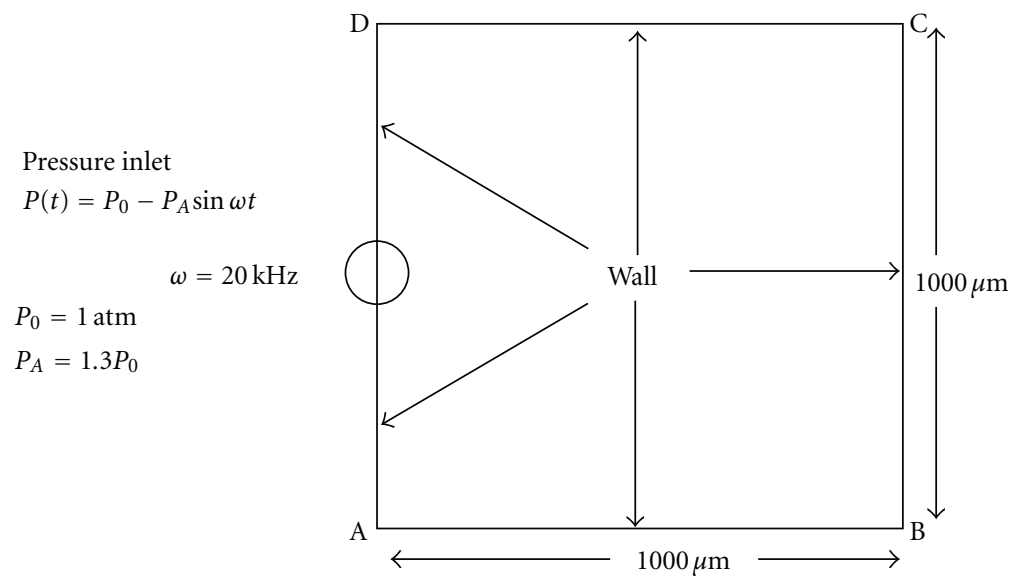

FIgURE 1: Schematic diagram of the domain with semicircular bubble wall.
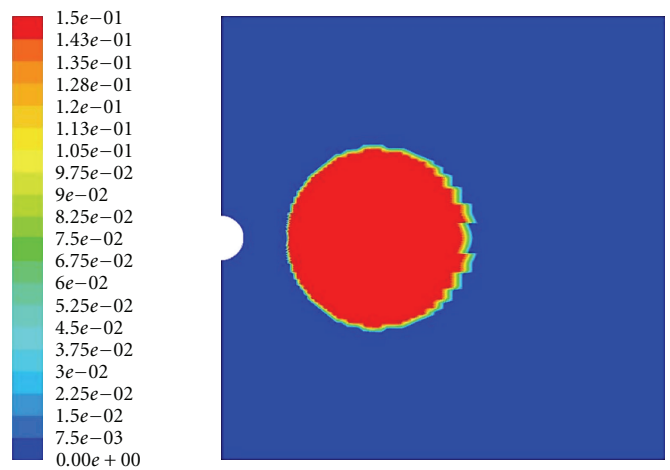

Figure 2: Contour of particulate volume fraction at time $t=0 \mathrm{~s}$.

at the boundaries does not make the problem far away from reality because the pushing effect of cavitation of different bubbles will be resulting in cancellation of flow along a boundary line surrounding each of the bubble.

It has been further assumed that size distribution is not present in the nanoparticles, that is, all the particles are of same size. Eulerian multiphase granular flow was assumed and solved using FLUENT 6.2.16. The volume element was divided into $2 \times 10^{4}$ control volumes. The region nearby the bubble was finely meshed to get the accurate calculation in that region as very high pressure is generated in the domain, which is affected largely by the region nearby bubble.

The Eulerian granular multiphase model solves a set of momentum and continuity equations for each phase. Coupling is achieved through the pressure and interphase exchange coefficients. In this problem, a combination of two phases, namely, fluid and solid has been taken. This is called granular flow problem. In granular flows, the properties are obtained from application of kinetic theory [13]. The standard $k-\varepsilon$ model [14] has been considered assuming the flow to be fully turbulent.

The Shyamlal et al. Equation [13], which takes into consideration the van der Waals force amongst the particles, was used for the particle-particle interaction.
Since $\mathrm{Al}$ is most widely used material as a matrix in composites, for the modeling of the nanoparticle deagglomeration we have chosen Aluminum as matrix material. The reinforcement in the matrix has been taken as $\mathrm{SiC}$ nanoparticles of $30 \mathrm{~nm}$ size. Along with this we have assumed that about $15 \mathrm{ppm}$ air is entrapped in the aluminum melt.

\section{Results and Discussions}

FLUENT 6.2.16 was run to simulate the mathematical model. The computational time step for solving the unsteady state problem was $0.1 \mu \mathrm{s}$. During the simulation of the model the output data files, namely, those containing information on velocity field and volume fraction (particulate) field were saved after every 100 time steps for computations up to the first 1000 time steps. Later on the frequency for saving the data files was reduced, that is, data files were saved after every 5000 time steps for the next 50000 time steps and after every 10000 time steps for the remaining computation.

The contours of volume fraction of particulate were plotted from the saved data files. Figure 2 shows the initial distribution of nanoparticles with respect to the source of the shock wave, that is, the location where periodic cavitations is occurring. Figure 3(a) shows the movement of the agglomerate of the nanoparticles in the first $100 \mu \mathrm{s}$. The lump moves towards the right boundary wall. As it moves its shape also changes. Apart from this convective movement the nanoparticles have diffused out to a small extent. Since bubble wall has been taken as semicircular, the shock wave generated by the bubble will be circular in nature. It can be seen from Figure 3(a), in which the nanoparticles lying on the symmetry axis, being closer to the bubble, have moved more compared to those at other locations. It can be seen from Figure 3(b) that after an initial drift towards the right wall the agglomerate bifurcates, and a spiral pattern on both the sides of the axis of symmetry is formed. Within the spiral pattern, a narrow band of zones with high volume fraction of nanoparticles can be observed. This convective effect is due to high fluid velocity created by the pressure field. A gradual 

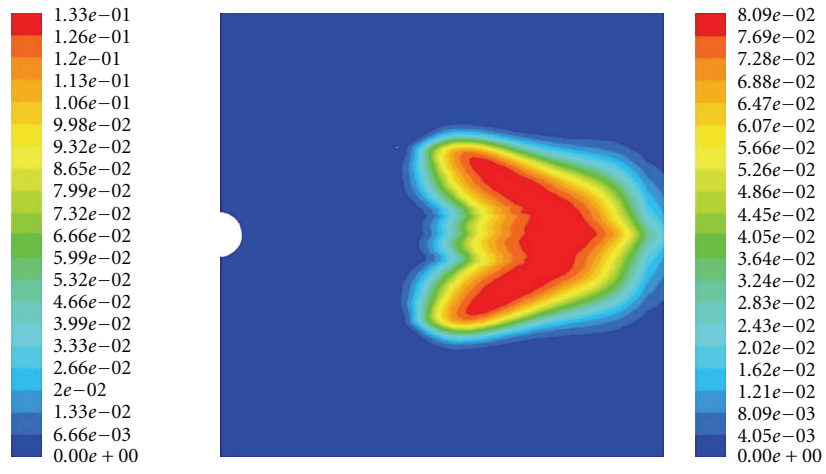

(a)
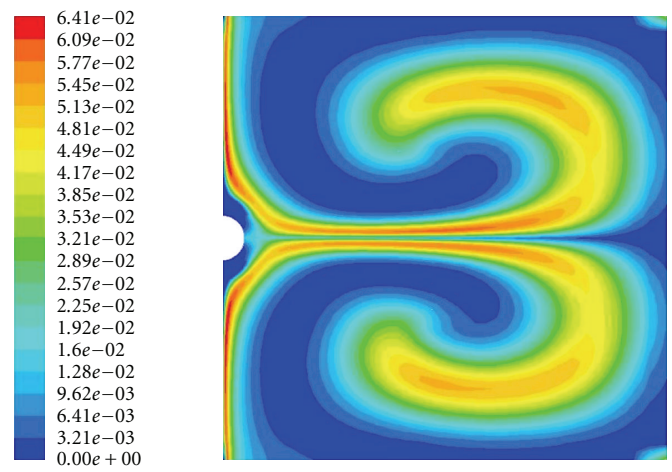

(c)
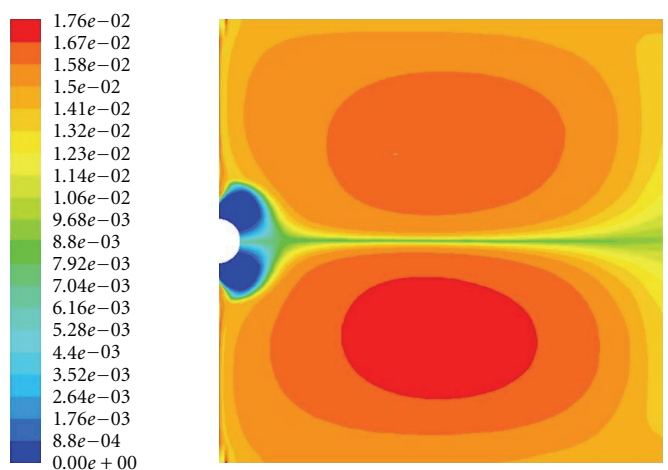

(e)
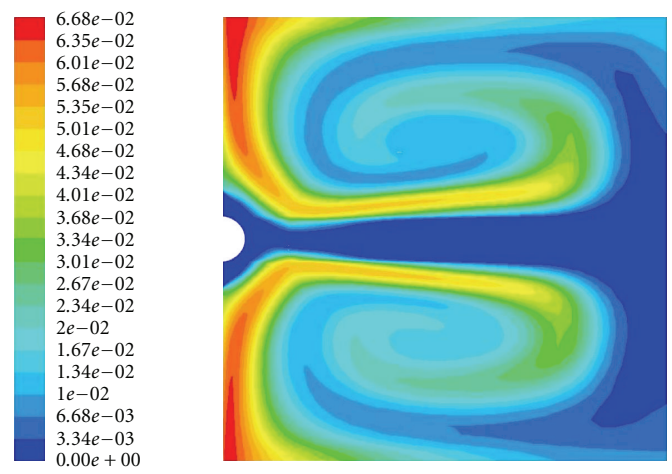

(g)

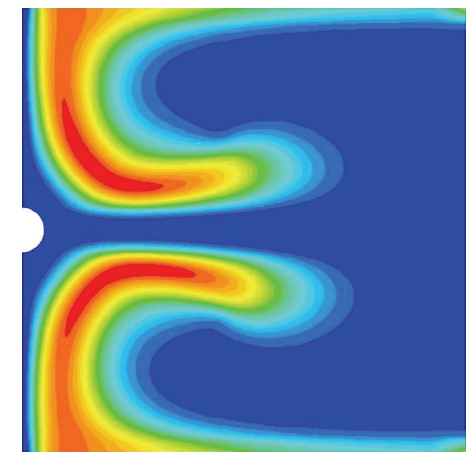

(b)

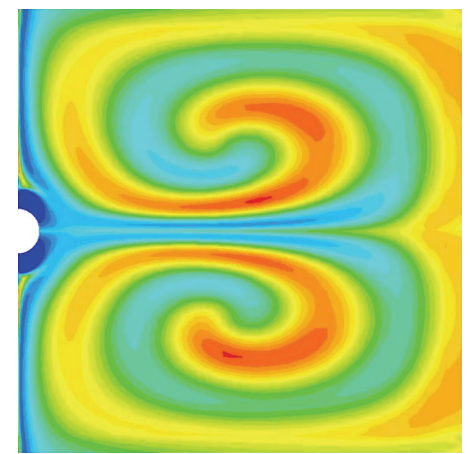

(d)

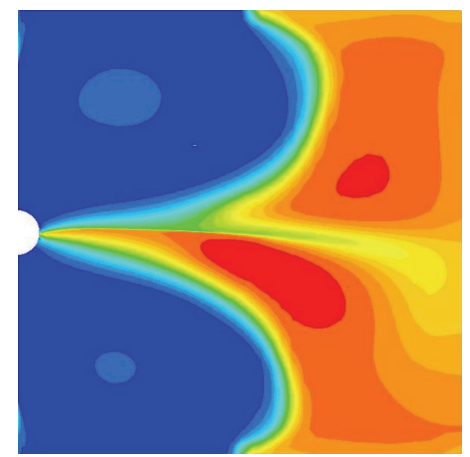

(f)

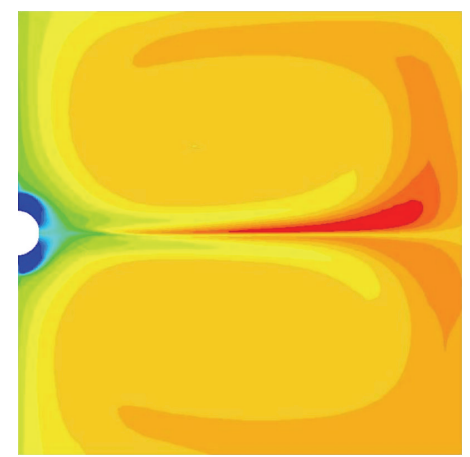

(h)

Figure 3: (a) Contour of particulate volume fraction at time $t=100 \mu \mathrm{s}$. (b) Contour of particulate volume fraction at time $t=1 \mathrm{~ms}$. (c) Contour of particulate volume fraction at time $t=2 \mathrm{~ms}$. (d) Contour of particulate volume fraction at time $t=4 \mathrm{~ms}$. (e) Contour of particulate volume fraction at time $t=15 \mathrm{~ms}$. (f) Contour of particulate volume fraction at time $t=50 \mathrm{~ms}$. (g) Contour of particulate volume fraction at time $t=0.4 \mathrm{~s}$. (h) Contour of particulate volume fraction at time $t=4.2 \mathrm{~s}$. 

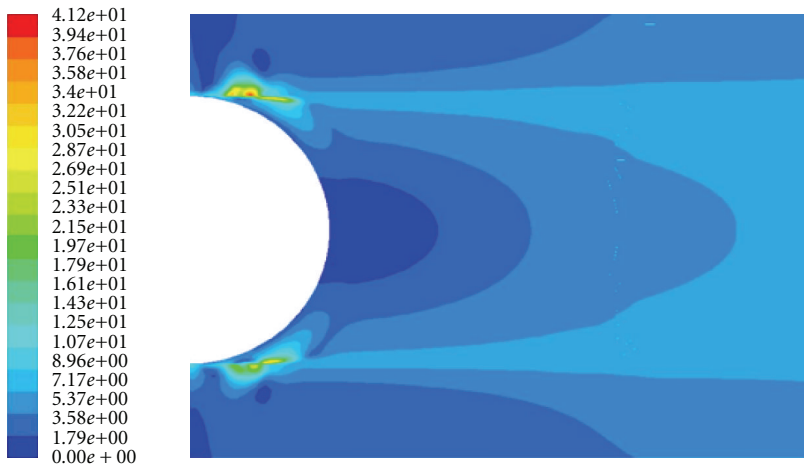

FIgURe 4: Contour of magnitude of velocity (liquid $\mathrm{Al}$ ) at time $t=$ $0.1 \mu \mathrm{s}$.

dispersion of the nanoparticles can be seen in Figures 3(b)3(e).

After the formation of spiral bands, as shown in Figures 3(b)-3(e), nano-particle depleted zones formed on both sides of the bubble. At $50 \mathrm{~ms}$ (Figure 3(f)) of simulation time almost half of the domain got depleted and nanoparticles were pushed towards the right side of the boundary. But in the nondepleted zone dispersion of nanoparticles has taken place. Thus a spiral pattern forms again. In earlier figures we have seen that how the nanoparticle agglomerate is moving away from the bubble. In subsequent figures, we have seen spiral loops and then nanoparticle-depleted regions. In Figure $3(\mathrm{~h})$, which is the contour after $4.2 \mathrm{~s}$, it can be noted that over a very large area the concentration of nanoparticle does not vary significantly. In the rest of the region, except very close to bubble gradient the concentration can be seen but this gradient can be neglected as it is very small. The volume fraction of particle did not change much with time, over a large area, after $4.2 \mathrm{~s}$. we can conclude that almost homogeneous distribution was achieved after $4.2 \mathrm{~s}$ throughout.

The contour of magnitude of velocity (liquid $\mathrm{Al}$ ) is shown in Figure 4. It can be seen that the maximum velocity of the fluid can rise up to $41 \mathrm{~m} / \mathrm{s}$ local to the bubble. In the intense flow field, which spatially varies over the agglomerate zone, different parts of the agglomerate are pushed in different direction, facilitating the movement of its different parts in different direction. Such a flow, with sharp variation in the velocity field is generated by the pressure shock wave with very low wavelength.

\section{Conclusions}

A flow within a representative volume element with a single agglomerated lump of the nanoparticles, as a result of periodic cavitation, has been simulated. After $\sim 4.2 \mathrm{~s}$ significant dispersion took place and the distribution of nanoparticles was almost uniform. Thus the phenomenon of deagglomeration due to cavitation could be simulated at mesoscale. Intense convective flow with significantly large gradient in the velocity fields, at the mesoscale, results in the dispersion.

\section{References}

[1] K. S. Suslick, Ultrasound: Its Chemical, Physical, and Biological Effects, Vancouver Coastal Health, New York, NY, USA, 1988.

[2] G. I. Eskin, Ultrasonic Treatment of Light Alloy Melts, Gordon and Breach, Amsterdam, The Netherlands, 1998.

[3] G. I. Eskin, Yu. P. Pimenov, and G. S. Makarov, "Effect of cavitation melt treatment on the structure refinement and property improvement in cast and deformed hypereutectic AlSi alloys," Materials Science Forum, vol. 242, pp. 65-70, 1997.

[4] G. I. Eskin, "Broad prospects for commercial application of the ultrasonic (cavitation) melt treatment of light alloys," Ultrasonics Sonochemistry, vol. 8, no. 3, pp. 319-325, 2001.

[5] G. I. Eskin, B. I. Semenov, and D. N. Lobkov, "Concept and control means for the formation of crystalline structure of castings in new casting methods," Litejnoe Proizvodstvo, no. 9, p. 2, 2001.

[6] D. G. Eskin, M. L. Kharakterova, G. I. Eskin, and YU. P. Pimenov, "Structure and phase composition of hypereutectic silumines intended for deformation," Izvestia Akademii nauk SSSR. Metally, no. 2, pp. 91-98, 1997.

[7] Y. Yang, J. Lan, and X. Li, "Study on bulk aluminium matrix nano-composite fabricated by ultrasonic dispersion of nanosized $\mathrm{SiC}$ particles in molten aluminium alloy," Materials Science and Engineering A, vol. 380, pp. 378-383, 2004.

[8] Y. Yang and X. Li, "Ultrasonic cavitation-based nanomanufacturing of bulk aluminum matrix nanocomposites," Journal of Manufacturing Science and Engineering, vol. 129, no. 2, pp. 252-255, 2007.

[9] G. I. Eskin and D. G. Eskin, "Production of natural and synthesized aluminum-based composite materials with the aid of ultrasonic (cavitation) treatment of the melt," Ultrasonics Sonochemistry, vol. 10, no. 4-5, pp. 297-301, 2003.

[10] B. P. Michael, "Single-bubble sonoluminescence," Reviews of Modern Physics, vol. 74, no. 2, pp. 425-484, 2002.

[11] T. Hielscher, "Ultrasonic production of nano-size dispersions and emulsions," in Dans European Nano Systems Worshop (ENS '05), Paris, France, 2005.

[12] FLUENT Tutorials.

[13] M. Syamlal, W. Rogers, and T. J. O'Brien, MFIX Documentation,1, Theory Guide, National Technical Information Service, Springfield, Va, USA, 1993, DOE/METC-94112K2K4, NTIS/DE9400087.

[14] D. G. Schaeffer, "Instability in the evolution equations describing incompressible granular flow," Journal of Differential Equations, vol. 66, no. 1, pp. 19-50, 1987. 

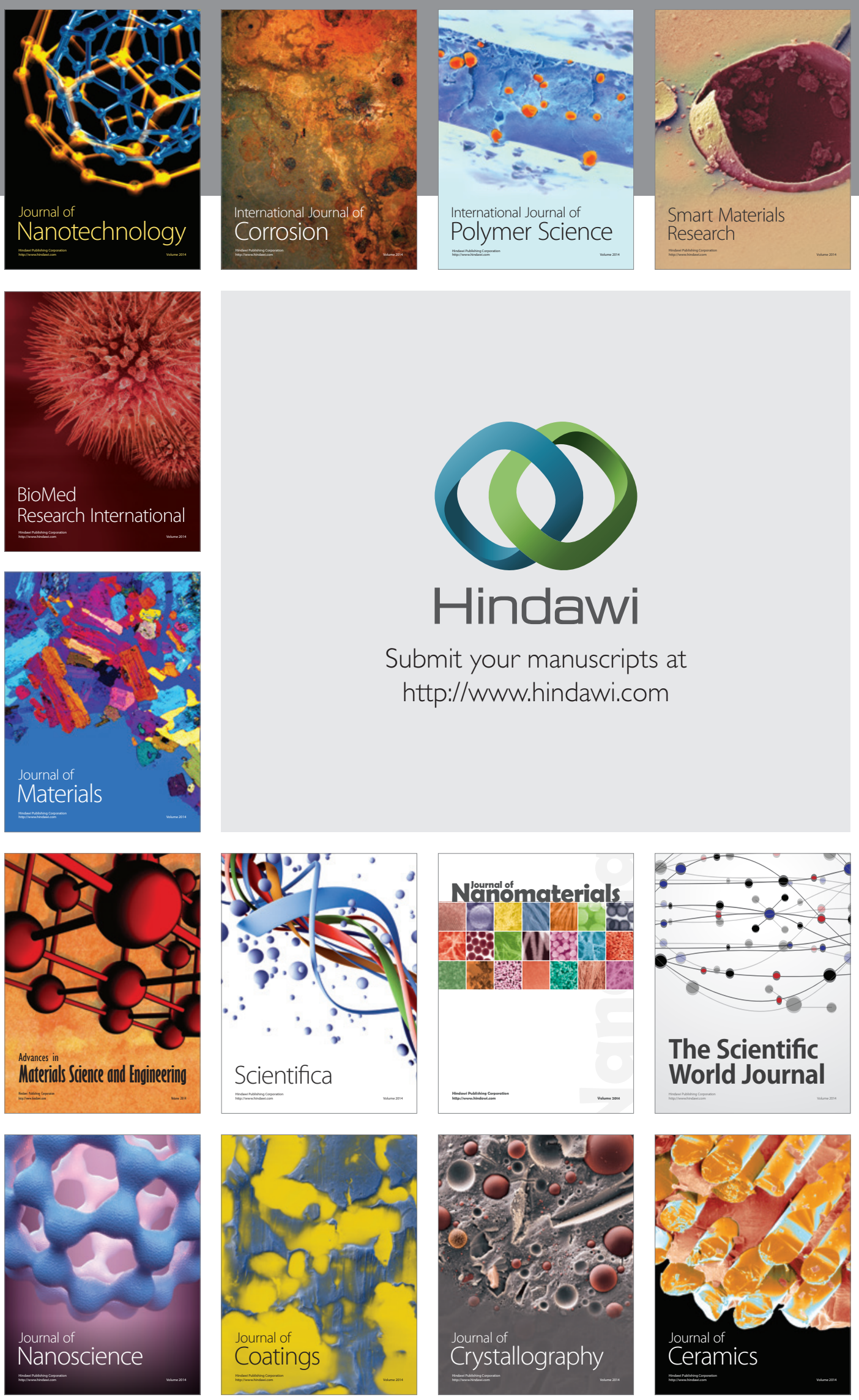

The Scientific World Journal

Submit your manuscripts at

http://www.hindawi.com

\section{World Journal}

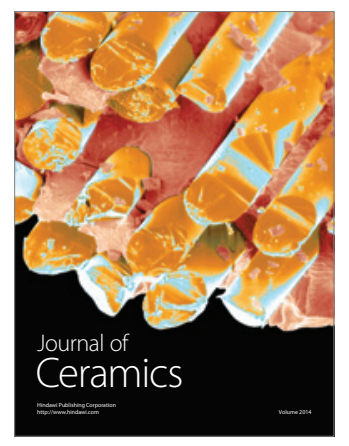

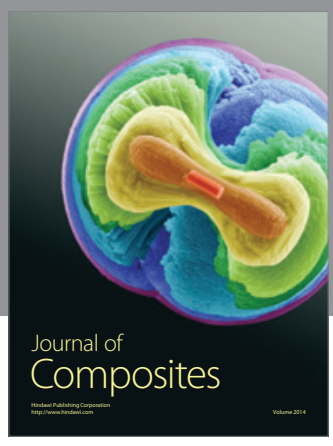
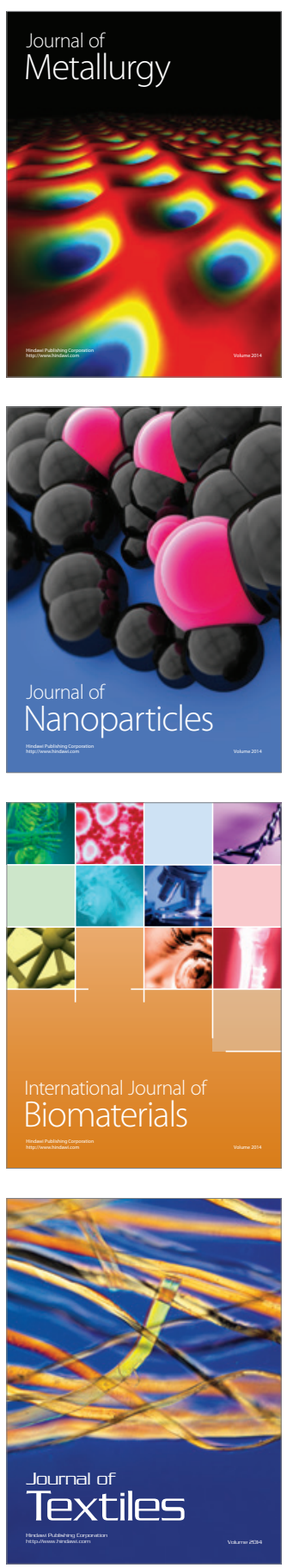